\title{
Evaluation of the Effect of Asset Market Fluctuations on the Financial Crisis of the Economy: An Application of Markov Switching
}

Submitted 10/06/21, 1st revision 11/07/21, 2nd revision 30/07/21, accepted 28/08/21

\author{
Neda Assadollahzadehjafari ${ }^{1}$, Bahar Hafezi ${ }^{2}$, Seyed Mohsen Khalifehsoltani ${ }^{3}$
}

\begin{abstract}
:
Purpose: The main purpose of this article is the effect of exchange rate fluctuations, oil prices, and stock market index on the financial instability index using the Markov switching rotation mode in 2009-2018 in the form of monthly data.

Design/Methodology/Approach: In this research, the Toolbox-Violet wavelet transform model has been used to extract the exchange rate fluctuations, oil prices, and stock market indices.

Findings: The results indicated that the effect of exchange rate fluctuations in various regimes and periods is different. Exchange rate fluctuations in the high regime of the financial instability index and the short term have a different effect compared to other periods. Oil price fluctuations have a positive and significant effect in the medium and long term, regardless of the financial instability regime, which will be more substantial in the long run. Moreover, stock market fluctuations have a negative and significant effect only in the short term when the financial instability index in the regime is low.

Practical implications: According to results of this article, fluctuations have different effects depending on the period and the level of financial instability. Therefore, the management of foreign exchange and stock markets in the country should be performed based on the level of financial instability and the period of fluctuations.

Originality/value: This research provides a new perspective on understanding the impact and transmission or fluctuations between markets and their impact on each other in recent decades.
\end{abstract}

Keywords: Exchange rate fluctuations, oil price fluctuations, stock fluctuations, Markov rotation model.

JEL codes: G12, E32, G01.

Paper type: Research article.

\footnotetext{
${ }^{l}$ PhD Student in Economics, Department of Economics, Khomeinishahr Branch, Islamic Azad University, Khomeinishahr, Isfahan,Iran. Neda.asadollahzadeh@iaukhsh.ac.ir ${ }^{2}$ Assistant Professor, Department of Economics, Khomeinishahr Branch, Islamic Azad University, Khomeinishahr, Isfahan,Iran.hafezi@iaukhsh.ac.ir;

${ }^{3}$ Assistant Professor, Department of Economics, Khomeinishahr Branch, Islamic Azad University, Khomeinishahr, Isfahan, Iran. Khalifehsoltani@iaukhsh.ac.ir
} 


\section{Introduction}

The banking system plays a vital role in Iran's economy as financial intermediation like many developing countries. The banking sector controls most financial flows and accounts for more than $87 \%$ of the economy financing. Therefore, a profitable and efficient banking sector ensures the efficiency of the entire financial system and thus economic growth and development. Iran's economy is going through one of the most sensitive and breathtaking periods of its life in the current situation for various reasons. In such circumstances, the financial system and especially the country's banking industry has a double and a heavy burden, and making this industry more efficient helps the country's economy. Efficiency is the optimal allocation of resources, which indicates the maximum use of resources or the tolerance of the minimum cost with the current technology. Thus, any waste of resources, inadequate structure in economic activities, unnecessary costs, unbalanced credit policies, redundant regulations, etc. will indicate the inability to allocate resources optimally and lack of economic efficiency.

Today, calculating efficiency in various organizations and industries is one of the necessary measures to compare competitiveness in the domestic and foreign scene, and banks are also affected by this rule. Calculating the efficiency of banks and recognizing their influential factors is essential (Hassanzadeh, 2011). The financial market plays a vital role in the general balance of the economy and the transmission of economic shocks in society as one of the financing methods and allocation of resources. The conditions of these markets strongly affect the real sectors of the economy and are influenced by other sectors. Instability in financial markets and banks causes a sharp decline in the supply of capital suppliers, credit and bank loans, a decline in bank customers' confidence in savings in banks, and, ultimately, a decline in production, income, and wealth.

Therefore, investigating the financial stability and its influential factors is essential in a region's economy because it can prevent some of these costs and improve economic growth and development. A well-functioning financial system indicates financial stability. This case is achieved through the optimal use of productive investment opportunities, while the malfunction of the financial system leads to financial instability through the inefficient allocation of scarce resources (Koong et al., 2017). Bank-centered financing in the country and high dependence of the country's economy on oil revenues, as well as the decisive role of oil revenues in the stability of exchange rates and import-centered capital and intermediate goods in the country, on which production and industry depend, show he importance of stability in asset markets to reduce financial crises. Most of the financial instability components in each country are changes in banking facilities granted by the banking network, changes in banking facilities granted to the private sector, changes in the liquidity, and changes in overdue receivables of the banking network (Batuo et al., 2018). 
According to the information and statistics published in the economic indicators of the Central Bank, liquidity in the country has reached 15299.8 thousand billion rials at the end of 2017, which has reached 15827.5 thousand billion rials in the first quarter of 2018. Liquidity in the first quarter of 2018 grew more than $102 \%$ compared to 2014. The non-performing loans' share in the total granted banking facilities has increased to $10.3 \%$ at the end of 2017 and $11.4 \%$ in the first quarter of 2018. The amount of banking facilities granted by the banking network has also increased from 7775.1 thousand billion Rials in 2014 to 13817 thousand billion Rials in the first quarter of 2018. The amount of banking facilities granted to the private sector has increased from 6309.6 trillion Rials in 2014 to 11050.9 trillion Rials in the first quarter of 2018 .

According to the published statistics, there has been significant growth in all variables that make up the financial volatility index in the country that can jeopardize financial stability in the country. Based on the country's reality, the stock, exchange, and oil markets have experienced significant fluctuations in recent years. On the other hand, fluctuations can have a different impact on financial instability in the country depending on the level and regime of instability according to the period of fluctuations. This research investigates whether the impact of exchange, oil, and stock asset fluctuations and the financial crisis in the country is different. This research is organized into five sections. In the second part, the theoretical foundations and research background are presented, and in the third part, the methodology is related to the model.

\subsection{Financial Instability}

Financial instability indicates a situation in which the financial system is not functioning well and cannot respond to economic shocks such as exchange rates and oil prices. Considering the significant role of the banking network in the country's financing and its high share of liquidity in the country, financial instability in the country is mainly related to the performance of the banking network in allocating resources and its ability to collect receivables.

\subsection{Exchange Rate Fluctuations}

The exchange rate is the relative price of domestic currency to foreign currency, which has always been considered by the economic and financial community. This rate reflects the country's economic conditions, which is a factor for comparing the national economy with the economies of other nations. Exchange rate fluctuations or positive or negative exchange rate shocks affect the demand and supply of the whole economy. Exchange rate fluctuations reduce purchasing power because an increase in the exchange rate leads to an increase in the price of imported goods, which can lead to a further increase in the exchange rate as a cause-and-effect relationship. Extreme exchange rate fluctuations lead exporters to either stop working or demand higher profits in exchange for more risk, given the degree of risk-taking. Since small 
countries do not have the power to set world prices, the increase in profits demanded by exporters and importers is offset by more expensive sales to buyers, resulting in nothing but rising prices and inflation. Thus, exchange rate fluctuations reduce domestic production and increase inflation (Sikwila, 2011).

\subsection{Stock Index Fluctuations}

The size of the capital market depends on the economic policies of each country. Bank-centered countries are more affected by liquidity-driven, from banks to the economy. In such countries, monetary policy is at the helm of their economies, but today, as noted, developed countries are moving towards liquidity from the capital market. Therefore, financing from the capital market has a special priority due to the mentioned cases, and most developing and emerging countries are moving towards the centrality of the capital market (Abbasi, 2009).

\section{Literature Review}

\subsection{Foreign Studies}

Bahmani, Oskooee, and Saha (2016) examined the asymmetric effects of exchange rate fluctuations on stock price indices in eleven different sectors in the United States. The asymmetry cointegration and nonlinear $\mathrm{ARDL}^{4}$ approach were used in this study. According to the research findings, changes in the effective nominal exchange rate had significant asymmetric effects on ten sectors in the short term. These asymmetric effects remain in 6 of these 11 segments in the long run. The devaluation of the dollar had a positive effect on their stock prices in 5 of these 6 sectors, while it did not.

Bianchi and Rebucci (2017) examined whether the ease of monetary policy in the United States using a stochastic dynamic general equilibrium model increases financial instability. According to the results, interest rate inflexibility in a monopoly banking network increases the likelihood of a financial crisis compared to a situation where interest rates are flexible. When interest rates are the only available tools, monetary policy is encountered with macroeconomics and financial stability. This exchange is quantitative and qualitative in the presence of contractionary policy and only quantitatively in response to the expansionary policy. The results show that another tool called the Pigovian tax provided to households on the market demand side effectively restored the economy's efficiency in the case of both frictions.

Partovi and Matousek (2019) conducted a study entitled "Banking Efficiency and Non-performing loans: Evidence from Turkey" to examine the banking efficiency from December 2003 to December 2017. They used the hypothesis of constant return to scale using the data envelopment analysis model focusing on non-

\footnotetext{
${ }^{4}$ Autoregressive distributed lag (ARDL).
} 
performing loans as the undesirable output. The quantile regression results indicated that non-performing loans have a negative impact on banking efficiency in this country and somehow confirm the hypothesis of bad management in the banking sector. The results showed that non-performing loans have a negative impact on the efficiency and stability of the bank as they degrade the quality of the bank's assets. In the current literature, non-performing loans are considered as a controlled variable or a bad output. All studies show that NPLs (non-performing loans) contribute to the inefficiency of banks. Some studies show that the main problem with NPL-based papers is that they assume NPLs as a controlled variable, not an undesirable output that directly affects the production process. Therefore, this paper considers NPL as an undesirable output. Radivojevic et al. (2019) conducted a study entitled "Econometric model of factors determining non-performing loans" using a dynamic panel data model for emerging Latin American countries. No evidence has been provided to prove that inflation and microeconomic variables affect non-performing loans in this study.

\subsection{Domestic Studies}

Valipour and Arbab (2016) investigated the effects of foreign exchange market instability on the efficiency of the country's banking network using the vector autoregression model. Their results show that Iranian banks do not suffer from foreign exchange market instability. Issues such as the recognition of profits in banks, the lack of laws and regulations related to bankruptcy, and banks' access to the foreign exchange market, provide special conditions for the Iranian banking network to distance itself from the losses caused by macroeconomic interactions. Ismaili (2018) investigated the role of business cycles in the overdue receivables of the country's banks using band-pass filters. The results showed that the overdue receivables of banks have a cyclical behavior that decreases during prosperity and increases during the recession.

Hakimipour (2018) has evaluated the impact of banking factors on non-performing loans of the country's banks using a dynamic panel data model. The results show that the past interruption of non-performing loans, the rate of return on equity, the ratio of banking facilities granted to assets, the ratio of equity to assets, and the rate of banking facilities granted have a significant impact on non-performing loans in the country's banks. No indexing has been made for financial instability so far in domestic studies, and the impact of fluctuations has not been studied due to its period and the level of financial instability. Fluctuations in different assets can have different effects depending on the period of the fluctuations and the level of financial instability.

\section{Research Methodology}

The purpose of this research is to investigate the effect of exchange rate fluctuations, oil prices, and stock index on the financial instability index from 2009:1 to 2017:12. 
The information of exchange rate, oil price, and stock price index from Ministry of Economy and Finance and information database related to the components of the financial instability index is also extracted from the economic indicators of the Central Bank. The component analysis approach is used based on the following equation in the present study to derive the factor of financial instability following the study of Batuo et al. (2018):

$$
I N S=G T C R * W_{i}+G P C R * W_{i}+G M_{2} * W_{i}+G D E B T * W_{i}
$$

The components of Equation (1) are as follows:

INS : Financial instability index

GTCR : Growth of granted banking facilities by the banking network

$G P C R$ : Growth of granted banking facilities to the private sector

$G M_{2}$ : Liquidity growth

$G D E B T$ : Total overdue receivables of the banking network

$W_{i}$ : The weight of the components.

Initially, the Daubechies wavelet transform is used to extract exchange rate fluctuations, oil prices, and stock price index from the approach, and Markov's rotational approach is applied to examine the effect of asset market fluctuations in the context of regime change. In nonlinear models, it is assumed that the behavior of the variable on which the modeling is performed is different and changes in different situations. Switching one regime to another in some of these nonlinear models is done slowly. Contrary to these models, the regime-switching in the Markov transfer model is considered exogenous (Enders, 2004). The models that are most considered in economic studies can be classified into four different modes, including the Markov-switching multifractal (MSM), Markov-switching interception (MSI), Markov switching models in autoregression model parameters (MSA), Markov switching heteroscedasticity (MSH).

$$
y_{t}=I+\sum_{i=1}^{p} A_{i} y_{t-i}+\varepsilon_{t} \rightarrow \begin{cases}I & =f\left(s_{t}\right) \rightarrow M S I \\ A_{i} & =f\left(s_{t}\right) \rightarrow M S A \\ \operatorname{var}\left(\varepsilon_{t}\right) & =f\left(s_{t}\right) \rightarrow M S H \\ \mu_{y} & =f\left(s_{t}\right) \rightarrow M S M\end{cases}
$$

In this equation, if the interception (I) is dependent on the regime, the model is (MSI) type. If the autoregressive component is dependent on the regime, the model is (MSA) type. If the heteroscedasticity is variable, the model is (MSH) type. If the model is Markov switching multifractal, it will be (MSM), while a combination of the above is used in some states.

\section{Research Findings}


According to the calculations, the results of the estimated weights are presented in Table 1:

Table 1. Estimation of Weights of financial instability index

\begin{tabular}{ccccc}
\hline Index & GTCR & GPCR & GM $_{2}$ & GDEBT \\
\hline INS & 0.532 & 0.554 & 0.372 & 0.520 \\
\hline
\end{tabular}

Source: Research Findings.

According to the extracted information, the financial instability index is as follows:

$$
I N S=G T C R * 0 / 532+G P C R * 0 / 554+G M 2 * 0 / 372+G D E B T * 0 / 520
$$

The following are the eigenvalues of the main components in Figure 1.

Figure 1. Component eigenvalues

Scree Plot (Ordered Eigenvalues)

$$
\begin{aligned}
& 3.0 \\
& 2.5 \\
& 2.0 \\
& 1.5 \\
& 1.0 \\
& 0.5 \\
& 0.0
\end{aligned}
$$

Source: Research Findings.

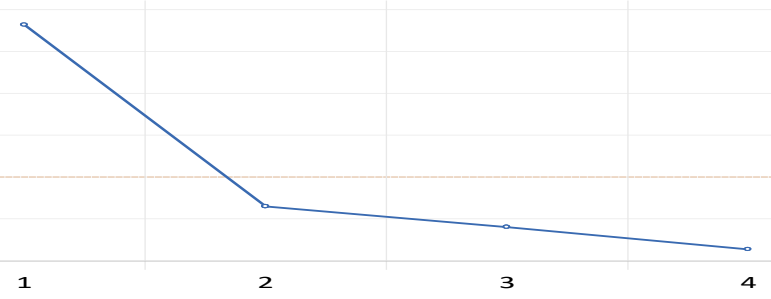

In Figure 1 the vertical axis represents the number of specific values of the financial instability components, and the horizontal axis represents the components of the financial instability index. Then, the variables of exchange rate instability, oil price, and stock price index were extracted using the wavelet transform model.

\subsection{Estimating the Variables of Exchange Rate Fluctuations, Oil Prices, and Stock Indices}

The wavelet transform approach has been used to estimate the instability. In this case, it is possible to study the effects of instability in different periods. The volatility variables of the asset markets are analyzed in three levels. For this reason, three levels of analysis are used, which are shown in the following Figures.

Figure 2. Levels of exchange rate logarithm analysis

Source: Research Findings.

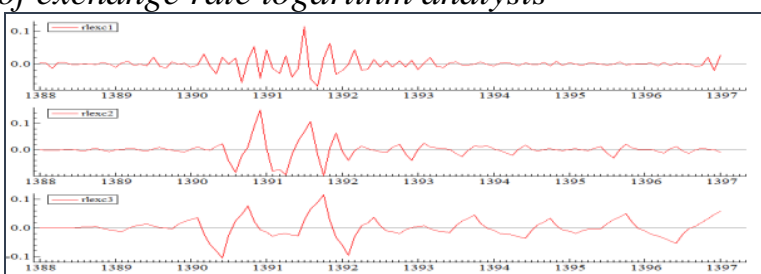


According to Figure 2, most short-term exchange rate fluctuations are in early 2011 to mid-2013. The most fluctuations in the medium term are in 2011 to early 2013. Most long-term fluctuations are related to the beginning of 2011 to mid-2013 and also mid-2017 to 2018. The different levels of oil price analysis are presented in Figure 3.

Figure 3. Level of oil price logarithm analysis

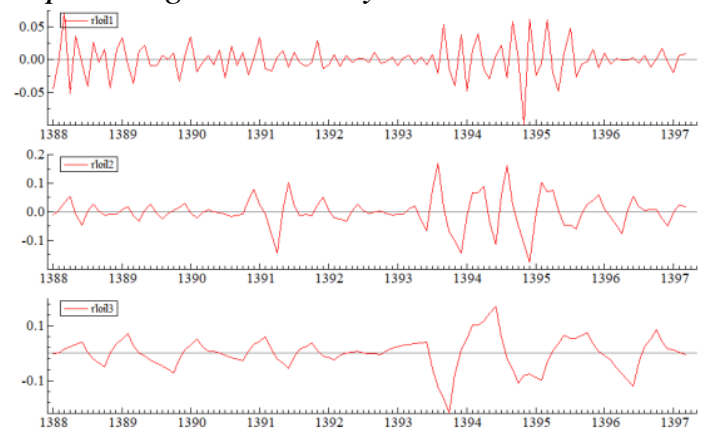

Source: Research Findings.

According to Figure 3, the logarithm of oil prices has experienced many fluctuations in the reviewed period and shows fewer fluctuations between 2011 and late 2014. Figure 2 is related to short-term fluctuations in oil prices, medium-term fluctuations in oil prices, and long-term fluctuations in oil prices. Figure 4 shows the different levels of stock price index analysis. Figure 3 is related to short-term stock index fluctuations, medium-term stock index fluctuations, and long-term stock index fluctuations.

Figure 4. Levels of stock price index analysis

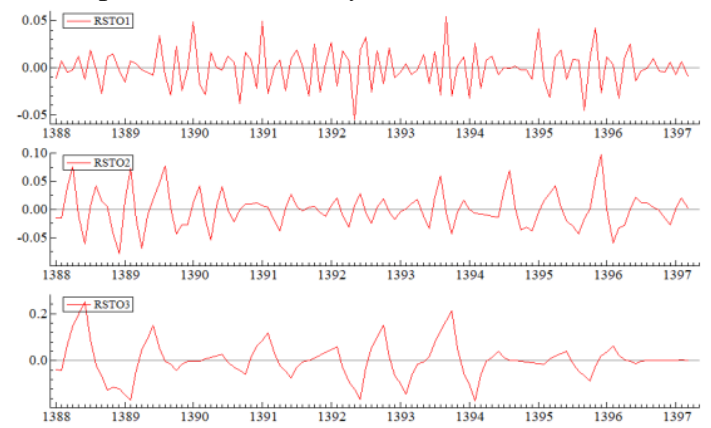

Source: Research Findings.

\subsection{Estimation of the Primary Research Model and Analysis of Findings}

This research investigates the effect of exchange rate logarithm, oil price logarithm, and stock index logarithm on the financial instability index in different regimes by Markov rotational model. 
Table 2. Model non-linearity test

\begin{tabular}{cccc}
\hline Statistics & $\begin{array}{c}\text { Statistics } \\
\text { value }\end{array}$ & $\begin{array}{c}\text { probability } \\
\text { level }\end{array}$ & Result \\
\hline $\mathrm{Chi}^{\wedge} 2$ & 50.64 & 0.000 & $\begin{array}{c}\text { The use of a nonlinear } \\
\text { model is approved. }\end{array}$ \\
\hline
\end{tabular}

Source: Research Findings.

According to studies of the information criteria of the research model, the optimal degree of auto-regression (AR) and the optimal degree of moving average (MA) are one, and the number of optimal regimes is 2. Therefore, the model is MSI_ARMA $(2,1,1,1)$. The results of estimating the above model are given in Table 3 .

Table 3. Estimation of research model

\begin{tabular}{ccccc}
\hline Variable & Coefficient & $\begin{array}{c}\text { Standard } \\
\text { deviation }\end{array}$ & T statistic & $\begin{array}{c}\text { probability } \\
\text { level }\end{array}$ \\
\hline AR-1(0) & 0.41 & 0.11 & 3.78 & 0.000 \\
AR-1(1) & 0.75 & 0.089 & 8.44 & 0.000 \\
MA-1(0) & -0.54 & 0.099 & -5.51 & 0.000 \\
MA-1(1) & -0.27 & 0.073 & -3.74 & 0.000 \\
C(0) & 0.077 & 0.01 & 7.56 & 0.000 \\
C(1) & 0.048 & 0.006 & 7.8 & 0.000 \\
Rlexc1(0) & -0.087 & 0.031 & -2.8 & 0.006 \\
Rlexc1 (1) & -0.027 & 0.003 & -9.1 & 0.000 \\
Rlexc2(0) & 0.144 & 0.017 & 8.46 & 0.000 \\
Rlexc2 (1) & 0.025 & 0.0035 & 7.15 & 0.000 \\
Rlexc3(0) & 0.234 & 0.093 & 2.52 & 0.013 \\
Rlexc3(1) & 0.121 & 0.046 & 2.61 & 0.011 \\
Rloil1(0) & -0.09 & 0.255 & -0.364 & 0.71 \\
Rloil1(1) & 0.074 & 0.058 & 1.28 & 0.188 \\
Rloil2(0) & 0.381 & 0.187 & 2.03 & 0.045 \\
Rloil2(1) & 0.088 & 0.0211 & 4.17 & 0.000 \\
Rloil3(0) & 0.472 & 0.231 & 2.04 & 0.044 \\
Rloil3(1) & 0.039 & 0.015 & 2.61 & 0.01 \\
Rsto1(0) & 0.121 & 0.38 & 0.319 & 0.75 \\
Rsto1(1) & -0.069 & 0.036 & -1.92 & 0.058 \\
Rsto2(0) & -0.18 & 0.271 & 0.66 & 0.51 \\
Rsto2(1) & 0.27 & 0.19 & 1.42 & 0.16 \\
Rsto3(0) & -0.232 & 0.72 & -0.32 & 0.73 \\
Rsto3(1) & 0.029 & 0.019 & 1.51 & 0.13 \\
Sigma(0) & 0.027 & 0.0043 & - & - \\
Sigma(1) & 0.0074 & 0.00072 & - & - \\
\hline
\end{tabular}

Source: Research Findings

According to studies, the intersection with the lowest coefficient indicates the low regime, and the intersection with the most significant coefficient indicates the high 
regime. Therefore, the zero regimes in the present study indicate the high regime of the financial instability index, and the one regime indicates the low regime. Shortterm exchange rate fluctuations have a negative and significant effect on financial instability in the high regime, which has a positive and significant effect when $f$ the financial instability index is in the low regime. Exchange revenue in the short term can meet part of the demands of the banking network because the index of financial instability is mainly related to banking conditions and facilities. Exchange rate fluctuations have a positive and significant effect over time and fluctuations in more extended periods regardless of the level and regime of financial instability.

This positive and significant effect will be more substantial in case of long-term fluctuations. The reason for this is the occurrence of actual effects of exchange rate fluctuations in more extended periods. Short-term oil price fluctuations do not have a significant effect on the financial instability index in both regimes. The reason is the occurrence of actual effects of exchange rate fluctuations in more extended periods. Short-term oil price fluctuations do not significantly affect the financial instability index in both regimes that positively and significantly affect the medium and long term. This effect will be more substantial in the long run and when financial instability is at its highest level. If the financial crisis in the country is at a high level regarding the fluctuations of the stock index, it cannot have a significant effect even in the short term, but if the financial instability is at a low level, it has a negative and significant effect. This case can be due to more confidence in the banking network when its instability is low. Therefore, people prefer to deposit in the banking network over-investing in the capital market. The following different regimes of financial instability index are presented in Figure 5:

Figure 5. Classification of regimes in the short term
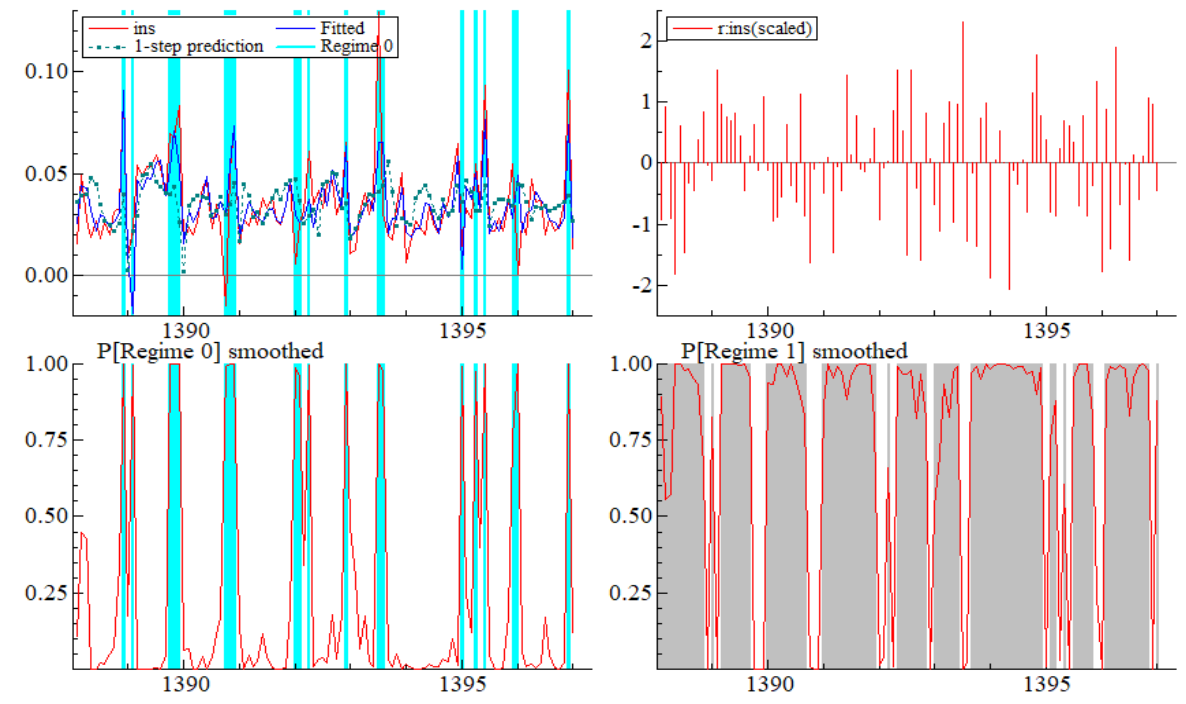

Source: Research Findings. 
Figure 5 shows that the number of months classified in regime one is more. The probability of regime transition is given in Table 4 .

Table 4. Probability of regime transition

\begin{tabular}{ccl}
\hline Regime One & Regime Zero & \\
\hline 0.54 & 0.47 & Regime Zero \\
0.73 & 0.17 & Regime One \\
\hline
\end{tabular}

Source: Research Findings.

According to the results of Table 4, regime one is more stable than regime zero, and the probability that the index of financial instability remains in regime zero or one is 0.47 and 0.73 , respectively. Therefore, the probability of transition from regime zero to regime one is 0.54 the probability of transition from regime one to regime zero is 0.17 . The stability of the low regime of financial instability is greater than the high regime.

\section{Conclusions and Recommendations}

The financial instability index was estimated based on bank-based components in this study, considering the reality of Iran's economy and the very high share of the banking network in financing. Then, stock index fluctuations, oil prices, and exchange rates were extracted using the wavelet transform model to different scales and times. Finally, Markov rotational model was used to estimate the primary research model. The instability of macroeconomic variables such as exchange rates, oil prices, and stock indices based on the reality of the country, as well as studies, can significantly affect financial instability. Banking components were used to estimate the financial instability index. The most important task of the banking sector is to collect deposits and provide banking facilities. Therefore, examining the effect of exchange rate fluctuations, stock index fluctuations, and oil price fluctuations on financial instability is essential in different periods.

The wavelet transform approach and the Daubechies discrete wavelet have been used to extract the mentioned fluctuations considering the time horizon. The results showed three levels of analysis and breakdown into short-term, medium-term, and long-term periods. Then their effect on financial instability was investigated using the Markov model at different levels of analysis.

The results show that exchange rate fluctuations in the short term and when financial instability is high is different from the low level. If the fluctuations in the foreign exchange market are not due to external factors such as sanctions, it should be done considering the level of financial instability because according to research findings, if financial instability in the country is at a low level with short-term exchange fluctuations, it can increase financial instability. The exchange fluctuations in the medium and long term will increase financial instability in the country, which will be more substantial when financial instability is at its highest level in the long run. 
Therefore, exchange fluctuations should be as short as possible and prevent further fluctuations. The greater the period of fluctuations in oil price fluctuations, the greater its positive impact on financial instability.

Given that exchange rate fluctuations can also be rooted in oil price fluctuations (changes in exchange supply) reducing and minimizing the dependence of the country's economy on oil revenues seems necessary and even more necessary in the current situation. Stock index fluctuations can reduce financial instability only in the short term and when financial instability is low. This issue and its ineffectiveness in more extended periods of time are due to the small share of the capital market in financing in the country, whose changes do not significantly effect on financial instability, especially in the long run.

Furthermore, its negative and significant short-term impact in low-level financial instability can be extended to other periods, provided that appropriate structures are created to further develop the capital market. The share of oil revenues in the country's budget should be reduced given the impact of oil price fluctuations over the long term, as well as the source of many exchange fluctuations because the exchange fluctuations will be less in such circumstances, and financial stability in the country will be less affected.

\section{References}

Abbasinejad, H., Ebrahimi, S. 2013. The effect of oil price fluctuations on the returns of the Tehran Stock Exchange. Quarterly Journal of Economic Research and Policy, 21(68), 83-108.

Bahmani-Oskooee, M., Saha, S. 2016. Asymmetry cointegration between the value of the dollar and sectoral stock indices in the US. International Review of Economics \& Finance, 46, 78-86.

Batuo, M., Mlambo, K., Asongu, S. 2018. Linkages between financial development, financial instability, financial liberalisation and economic growth in Africa. Research in International Business and Finance, 45, 168-179.

Cesa-Bianchi, A., Rebucci, A. 2017. Does easing monetary policy increase financial instability? Journal of Financial Stability, 30, 111-125.

Enders, W. 2004. Applied time series econometrics. Hoboken: John Wiley and Sons.

Hakimipour, N. 2018. Investigating Banking Factors on Non-performing loans of Iranian Banks (GMM Dynamic Panel Model Approach). Financial Economics Quarterly, 12(42), 99-119.

Hassanzadeh, R., Taghizadeh, H., Rezaei, A. 2011. The effect of shareholder composition on the information content of accounting profits of listed companies. Quarterly Journal of Accounting and Financial Research, 3, 107-124.

Ismaili, B. 2018. The role of business cycles in the overdue receivables of the country's banks using intermediate filters. Quarterly Journal of Financial Economics, 12(44), 161-188.

Khochiani, R. 2018. Investigating the time-scale interactions between stock price index and exchange rate fluctuations in Tehran Stock Exchange. Financial Management Strategy Quarterly, 6(21), 159-182. 
Koong, S.S., Law, S.H., Ibrahim, M.H. 2017. Credit expansion and financial stability in Malaysia. Economic Modelling, 61, 339-350.

Partovi, E., Matousek, R. 2019. Bank efficiency and non-performing loans: Evidence from Turkey. Research in International Business and Finance, 48, 287-309.

Radivojević, N., Cvijanović, D., Sekulic, D., Pavlovic, D., Jovic, S., Maksimović, G. 2019. Econometric model of non-performing loans determinants. Physica A: Statistical Mechanics and its Applications, 520, 481-488.

Raufi, A., Mohammadi, T. 2018. Predicting Tehran Stock Market Returns Using a Combination of Wavelet Decomposition and Adaptive Fuzzy Neural Network. Iranian Economic Research Quarterly, 23(76), 107-136.

Sikwila, M.N. 2011. Inflation Impact of an Exchange Rate Adjustment: The Case of Zimbabwe. Management, Informatics and Research Design, 166.

Vali Pourpashah, M., Arbab Afzali, M. 2016. The effects of foreign exchange market instability on the efficiency of Iran's banking network. Policy Article of the Central Bank of the Islamic Republic of Iran. 